\section{Case Reports in Neurology}

Case Rep Neurol 2020;12:266-269

DOI: $10.1159 / 000508760$

Published online: September 10, 2020

(c) 2020 The Author(s)

Published by S. Karger AG, Basel

www.karger.com/crn

This article is licensed under the Creative Commons Attribution-NonCommercial 4.0 International License (CC BY-NC) (http://www.karger.com/Services/OpenAccessLicense). Usage and distribution for commercial purposes requires written permission.

\title{
Hypertension-Related Cerebral Microbleeds
}

\author{
Sujan T. Reddy Sean I. Savitz \\ Department of Neurology, Institute for Stroke and Cerebrovascular Disease, University of \\ Texas Health Science Center at Houston, Houston, TX, USA
}

\section{Keywords}

Hypertension · Cerebral microhemorrhage $\cdot$ Intracerebral hemorrhage

\begin{abstract}
Hypertension and cerebral amyloid angiopathy are the most common causes of cerebral microbleeds. The pattern of microbleeds on T2*-weighted gradient echo sequence of magnetic resonance imaging of the brain can be indicative of the etiology of intracerebral hemorrhage. We describe a case of cerebellar hemorrhage with cerebral microbleeds secondary to chronic hypertension.

(C) 2020 The Author(s)

Published by S. Karger AG, Basel
\end{abstract}

\section{Introduction}

Cerebral microbleeds are now considered meaningful imaging markers of microangiopathy and represent focal accumulations of hemosiderin-containing macrophages [1]. Hypertension and cerebral amyloid angiopathy are the most common causes of cerebral microbleeds [2]. The pattern of microbleeds on imaging can be indicative of the etiology of intracerebral hemorrhage [3]. 


\section{Case Reports in Neurology}

Reddy and Savitz: Hypertension-Related Cerebral Microbleeds

\section{Case Report}

A 52-year-old man with poorly controlled hypertension, diabetes mellitus type 2 , and a left putamen subcortical ischemic stroke, who was noncompliant with medications, presented with right-sided weakness. On arrival his blood pressure was 218/125 mm Hg. Physical examination revealed dysarthria, right hemiparesis, and ataxia of the right hemi-body. Magnetic resonance imaging (MRI) of the brain showed right cerebellar hemorrhage and multiple extensive foci of susceptibility on gradient sequence, predominantly centered within the basal ganglia, thalami, brainstem, and deep and subcortical white matter of both cerebral and cerebellar hemispheres (shown in Fig. 1). Additionally, brain MRI also demonstrated extensive T2 hyperintensities within periventricular and deep white matter as well as the right thalamus and pons which could reflect chronic microvascular ischemic changes. Electrocardiogram and echocardiogram demonstrated severe concentric left ventricular hypertrophy, and admission urinalysis revealed proteinuria consistent with end-organ injury of hypertension [4]. Basic metabolic panel showed preserved renal function with an estimated glomerular filtration rate of $106 \mathrm{~mL} / \mathrm{min} / 1.73 \mathrm{~m}^{2}$. Cerebral amyloid angiopathy was considered in this patient; however, the distribution of microhemorrhages, the patient's age, and absence of cognitive impairment (determined based on neurological examination) argued against this diagnosis. He was diagnosed with hypertensive hemorrhage. He was started on carvedilol and lisinopril for hypertension and discharged home with outpatient physical therapy. At discharge and 1-month follow-up clinic visit, the patient continued to exhibit residual dysarthria and right hemiparesis. A review of home blood pressure log during the clinic visit demonstrated elevated blood pressure despite maximal doses of amlodipine, carvedilol, and lisinopril. Consequently, clonidine was added to his antihypertensive regimen. Workup for resistant hypertension was planned; however, the patient was lost to follow-up after the first clinic visit.

\section{Discussion}

T2*-weighted gradient echo or susceptibility-weighted imaging on MRI has enabled detection of the location of cerebral microbleeds. Approximately $80 \%$ of patients with intracerebral hemorrhage exhibit cerebral microbleeds [1]. The pattern of cerebral microbleeds is indicative of the cause of intracerebral hemorrhage. Lobar microhemorrhages are typically seen in cerebral amyloid angiopathy caused due to accumulation of abnormal amyloid protein in the vessel wall [1], whereas hypertensive microhemorrhages are commonly seen in the deep and infratentorial regions of the brain [3]. The deep and infratentorial location of microhemorrhages and evidence of end-organ injury in the heart and kidney in our patient were consistent with hypertensive cerebral microbleeds.

\section{Statement of Ethics}

Patient consent was not obtained due to de-identified information and images, and the retrospective nature of the study. Per our IRB requirements, CPHS/IRB review was waived. 


\section{Case Reports in Neurology}

\section{Conflict of Interest Statement}

The authors have no conflicts of interest to declare relevant to this study.

\section{Funding Sources}

NIH Stroke Net grant funding (U24 NS107322) to Sujan T. Reddy

\section{Author Contributions}

Sujan T. Reddy: data acquisition, drafting, and revision. Sean I. Savitz: drafting and revision of the manuscript.

\section{References}

1 Haller S, Vernooij MW, Kuijer JP, Larsson EM, Jäger HR, Barkhof F. Cerebral Microbleeds: Imaging and Clinical Significance. Radiology. 2018 Apr;287(1):11-28.

2 Kidwell CS, Greenberg SM. Red meets white: do microbleeds link hemorrhagic and ischemic cerebrovascular disease? Neurology. 2009 Nov;73(20):1614-5.

3 Kidwell CS, Wintermark M. Imaging of intracranial haemorrhage. Lancet Neurol. 2008 Mar;7(3):256-67.

4 Bakris G. Proteinuria: a link to understanding changes in vascular compliance? Hypertension. 2005 Sep;46(3):473-4 
Case Reports in Neurology

\begin{tabular}{l|l}
\hline Case Rep Neurol 2020;12:266-269 \\
\hline DOI: 10.1159/000508760 & $\begin{array}{l}\text { @ 2020 The Author(s). Published by S. Karger AG, Basel } \\
\text { www.karger.com/crn }\end{array}$ \\
\hline
\end{tabular}

Reddy and Savitz: Hypertension-Related Cerebral Microbleeds

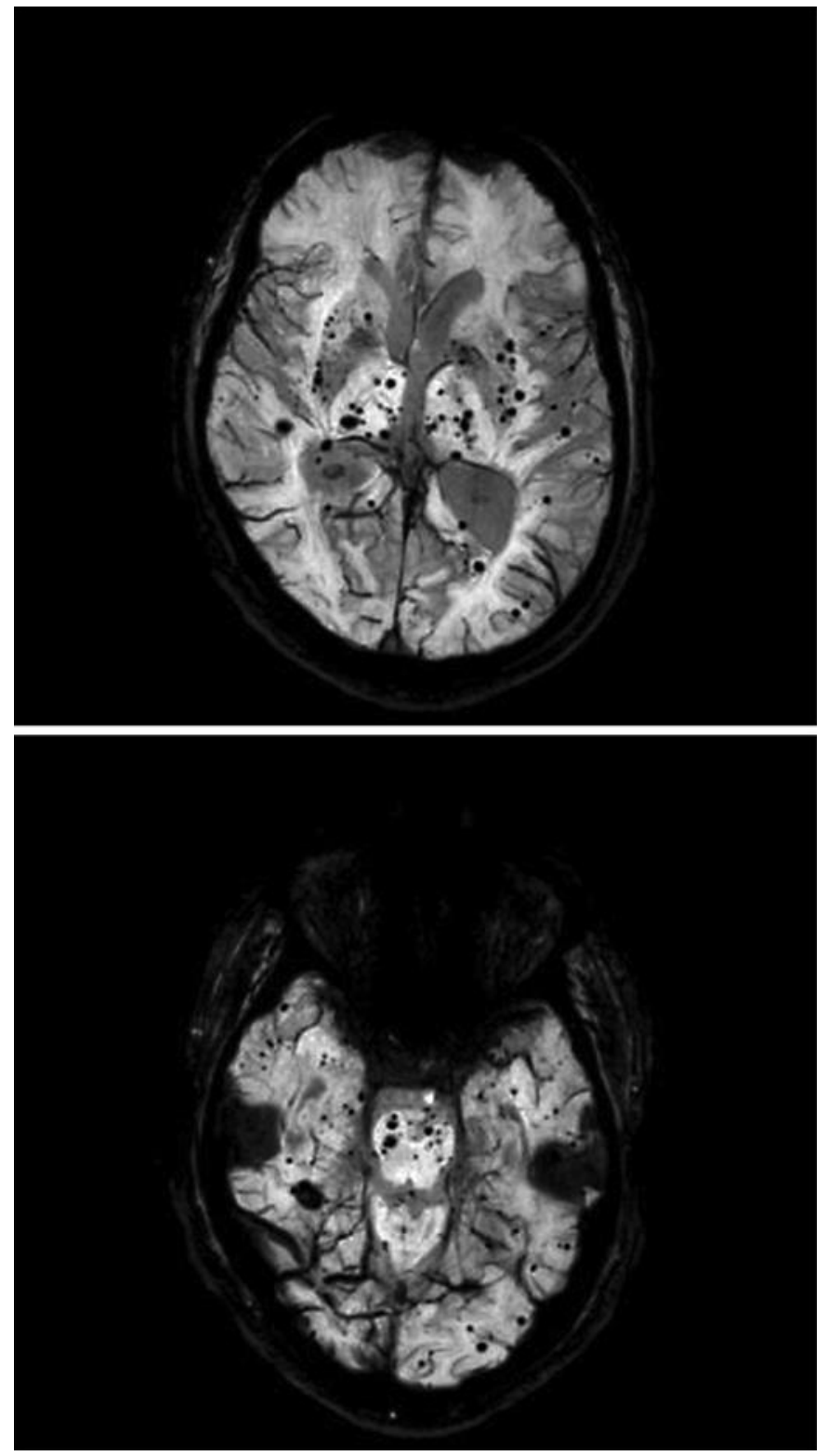

Fig. 1. MRI brain showing multiple extensive foci of susceptibility on gradient sequence predominantly centered within the basal ganglia, thalami, brainstem, and deep and subcortical white matter of both cerebral and cerebellar hemispheres. 